\title{
СТАТИСТИЧЕСКИЕ СВОЙСТВА ПОКАЗАТЕЛЕЙ РОСТА И ПЛОДОНОШЕНИЯ СМОРОДИНЫ
}

\author{
N.E. Makova, O.E. Bogdanov
}

\section{STATISTICAL PROPERTIES OF INDICATORS OF GROWTH AND FRUITING OF CURRANTS}

Макова Наталья Евгеньевна - канд. с.-х. наук, доц. каф. математики, физики и информационных технологий Мичуринского государственного аграрного университета, Тамбовская обл., г. Мичуринск. E-mail: nemakova@mail.ru

Богданов Олег Евгеньевич - канд. с.-х. наук, доц. каф. ландшафттной архитектуры, землеустройства и кадастров Мичуринского государственного аграрного университета, Тамбовская обл., г. Мичуринск. E-mail: bogdanov_o_e@mail.ru

Цель исследования - оценка степени варьирования показателей роста и плодоношения различных сортов черной смородины, выявление корреляционных связей между отдельными показателями. Исследования проводились на экспериментальных участках отдела ягодных культур ФГБНУ «ФНЦ им. И.В. Мичурина». Участки заложены по схеме 4,0 × 0,75 м. В качестве биологических объектов исследования взяты растения шести сортов смородины черной в количестве 50 шт. по каждому сорту. Растения выбирались случайно, в фазу плодоношения. Замеры производились на типичных побегах. Измерения высоты ветви и длины плодоносящей зоны проводились с помощью рулетки, приборная погрешность составляла 0,1 см. Урожай (общая масса ягод) с куста определялся по формуле: $\mathrm{V}=\mathrm{A} \cdot \mathrm{B} \cdot \mathrm{C}$, где $A$ - общее количество ягод на 1 ветви, шт.; $B$ средний вес одной ягоды, г; С - количество плодоносящих ветвей куста, шт. Периметр и площадь листовой пластинки определялись на основе ее изображения, полученного путем сканирования с высоким разрешением, с использованием компьютерной программой Leaf. Проведена статистическая обработка измерений показателей роста и плодоношения смородины черной, получены сведения о репрезентативности выборок, вариабельности показателей, применении статистических методов в оценке различий. Произведена оценка вариабельности, достоверности и точности
Makova Natalya Evgenyevna - Cand. Agr. Sci., Assoc. Prof., Chair of Mathematics, Physics and Information Technologies, Michurinsk State Agrarian University, Tambov Region, Michurinsk.

E-mail: nemakova@mail.ru

Bogdanov Oleg Evgenyevich - Cand. Agr. Sci., Assoc. Prof., Chair of Landscape Architecture, Land Management and Inventories, Michurinsk State Agrarian University, Tambov Region, Michurinsk. E-mail: bogdanov_o_e@mail.ru

биометрических показателей листьев смородины на основе оцифрованных сканированных изображений. Получены значимые корреляции между параметрами роста и плодоношения смородины, проведен анализ показателей листовых пластин и их связь с урожайностью. Установлена оптимальная площадь листьев, приходящаяся на одну ягоду (5,2-5,4 кв. см). Установлены корреляционные связи между количеством ягод и количеством листьев на одном побеге $(r=0,79)$, величиной урожая ягод с куста и количества листьев $(r=0,75)$. Выделены сорта с высокими уровнями компонентов продуктивности - Черный жемчуг, Чернавка и Маленький прини.

Ключевые слова: смородина, вариационная статистика, френотип, генотип, модификационная изменчивость.

The research objective was the assessment of the degree of the variation of indicators of growth and fructification of different blackcurrant varieties, the identification of correlation communications between separate indicators. The researches were conducted on experimental sites of the department of berry cultures of FSSI "I.V. Michurin FSC". The sites were put according to the scheme $4.0 \times 0.75 \mathrm{~m}$. As biological objects of the research the plants of six varieties of blackcurrant numbering 50 pieces on each variety were taken. The plants got out incidentally, in fruiting stage. The measurements were made on typical shoots. The measurements of the 
height of a branch and the length of fructifying zone were carried out by means of the roulette, the instrument error made $0.1 \mathrm{~cm}$. The crop (lump of berries) from the bush was determined by the formula: $Y=A \cdot B \cdot C$ where $A-$ total number of berries on a branch, ps; $B$ - average weight of one berry; $C$ the quantity of fructifying branches of a bush, ps. The perimeter and the area of a leaf plate decided on the basis of its image received by scanning with high resolution on use by the computer Leaf program. Statistical processing of the measurements of the indicators of growth and fructification of blackcurrant was carried out; the data on the representativeness of selections, variability of indicators, the application of statistical methods in the assessment of distinctions were received. The assessment of variability, reliability and accuracy of biometric indicators of leaves of currant on the basis of the digitized scanned images was made. Significant correlations between the parameters of growth and fructification of currant were received; the analysis of indicators of leaf plates and their communication with productivity was carried out. The optimum area of leaves falling on one berry $(5.2-5.4$ sq. $\mathrm{cm}$ ) was established. Correlation connection between the amount of berries and the quantity of leaves on one shoot $(r=0.79)$, the size of the yield of berries from a bush and the quantity of leaves was established $(r=0.75)$. The varieties with high levels of efficiency components were Cherny zhemchug, Chernavka and Malenky Prints.

Keywords: currant, variation statistics, phenotype, genotype, modification variability.

Введение. Качество и эфффективность научных исследований аграрной сферы в значительной степени связаны с уровнем использования математического моделирования экспериментальных данных, открывающего новые возможности и перспективы [1]. При решении многих теоретических и практических задач садоводства большое значение имеет выяснение закономерностей варьирования биометрических признаков растений.

Вариационная статистика выполняет в плодоводстве важные задачи - по планированию экспериментов, ориентированных на максимальное получение информации при минимальных затратах, использованию алгоритмов и методов оценки результатов исследований, установлению различных корреляционнорегрессионных и других связей и зависимостей между показателями роста и плодоношения плодовых и ягодных растений, прогнозированию и моделированию признаков, сортов, технологий, урожайности насаждений и культур.

Изучение модификационной изменчивости количественных признаков и выявление закономерностей их варьирования у растений имеет первостепенное значение для селекции, так как этот тип изменчивости является главным препятствием на пути повышения эффрективности идентификации по фенотипу нужных селекционеру генотипов и их отбора [2].

Цель исследования: оценка степени варьирования показателей роста и плодоношения различных сортов черной смородины, выявление корреляционных связей между отдельными показателями, а также между показателями роста и урожайности на основе предварительного анализа выборок.

Материалы и методы исследования. С целью проведения анализа сортовых различий и генетической вариабельности смородины внутри сорта были проведены измерения нескольких показателей роста и фенотипических параметров. Исследование проводилось на экспериментальных участках отдела ягодных культур ФГБНУ «ФНЦ им. И.В. Мичурина». Участки заложены по схеме 4,0 × 0,75 м. В качестве биологических объектов исследования взяты растения шести сортов смородины черной в количестве 50 шт. по каждому сорту. По мнению ряда авторов, такого количества объектов достаточно для нахождения зависимостей с приемлемой точностью [3]. Растения выбирались случайно, в фазу плодоношения. Замеры производились на типичных побегах.

Измерения высоты ветви и длины плодоносящей зоны проводились с помощью рулетки, приборная погрешность составляла 0,1 см. Урожай (общая масса ягод) с куста определялся по формуле $\mathrm{Y}=\mathrm{A} \cdot \mathrm{B} \cdot \mathrm{C}$, где А - общее количество ягод на 1 ветви, шт.; В - средний вес одной ягоды, г; С - количество плодоносящих ветвей куста, шт. Периметр и площадь листовой пластинки определялись на основе ее изображения, полученного путем сканирования с высоким разрешением, с использованием компьютерной программы Leaf [4].

Результаты исследования и их анализ. Эмпирические данные были обработаны стандартными методами вариационной статистики, получены численные значения таких статистических параметров, как среднее арифрметическое $M$, ошибка средней арифметической $m$, 
среднее квадратическое отклонение $\sigma$, точность опыта $p$, достоверность определения среднего по Стьюденту $t$ и коэффрициент вариации выборки V. Численные значения этих величин приведены в таблице 1.

Наиболее точно получены средние величины линейных замеров: высоты побегов ( $p=0,73$ $1,40 \%)$ и длины плодоносящей зоны ( $p=2,23$ $3,37 \%$ ), здесь же наблюдался наименьший коэфрфициент вариации.

Судя по значениям коэффрициента Стьюдента, определение средних значений по всем биометрическим показателям является достоверным.

Ошибка среднего арифметического не превосходит 5 \% по всем параметрам, кроме таких показателей, как «количество ягод» и «урожай с куста». Для этих параметров характерна также высокая изменчивость и вариабельность.

Наиболее высокорослыми побегами обладают сорта Маленький принц и Чернавка, низкорослыми - Зеленая дымка и Багира. По длине плодоносящей зоны и количеству листьев лидируют сорта Маленький принц и Черный жемчуг.

\section{Вариационно-статистические характеристики показателей роста и плодоношения смородины}

Таблица 1

\begin{tabular}{|c|c|c|c|c|c|c|c|}
\hline Сорт & Показатель & M & $\sigma$ & $\mathrm{m}$ & $p$ & $\mathrm{t}$ & V \\
\hline 1 & 2 & 3 & 4 & 5 & 6 & 7 & 8 \\
\hline \multirow{8}{*}{ 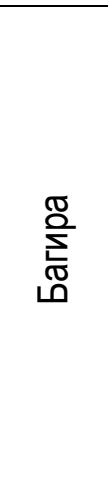 } & Высота ветви, см & 120,93 & 9,48 & 1,34 & 1,11 & 90,18 & 7,84 \\
\hline & Длина плод. зоны ветви, см & 53,53 & 8,44 & 1,19 & 2,23 & 44,84 & 15,77 \\
\hline & Кол-во листьев на 1 ветви, шт. & 85,07 & 22,56 & 3,19 & 3,75 & 26,67 & 26,52 \\
\hline & Кол-во ягод на 1 ветви, шт. & 374,00 & 146,91 & 20,78 & 5,56 & 18,00 & 39,28 \\
\hline & Урожай с куста, г & 5099,16 & 2194,80 & 310,39 & 6,09 & 16,43 & 43,04 \\
\hline & Кол-во плод. ветвей, шт. & 12,40 & 1,82 & 0,26 & 2,07 & 48,27 & 14,65 \\
\hline & Периметр листа, см & 28,41 & 8,30 & 1,17 & 4,13 & 24,20 & 29,22 \\
\hline & Площадь листа, кв. см & 25,88 & 11,76 & 1,66 & 6,42 & 15,56 & 45,43 \\
\hline \multirow{8}{*}{ 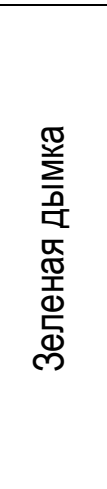 } & Высота ветви, см & 115,07 & 11,29 & 1,60 & 1,39 & 72,10 & 9,81 \\
\hline & Длина плод. зоны ветви, см & 55,07 & 13,11 & 1,85 & 3,37 & 29,71 & 23,80 \\
\hline & Кол-во листьев на 1 ветви, шт. & 84,20 & 34,95 & 4,94 & 5,87 & 17,03 & 41,51 \\
\hline & Кол-во ягод на 1 ветви, шт. & 324,33 & 145,07 & 20,52 & 6,33 & 15,81 & 44,73 \\
\hline & Урожай с куста, г & 5090,56 & 2115,78 & 299,22 & 5,88 & 17,01 & 41,56 \\
\hline & Кол-во плод. ветвей, шт. & 13,20 & 0,84 & 0,12 & 0,90 & 111,56 & 6,34 \\
\hline & Периметр листа, см & 23,26 & 6,11 & 0,86 & 3,72 & 26,91 & 26,27 \\
\hline & Площадь листа, кв. см. & 17,89 & 7,72 & 1,09 & 6,10 & 16,39 & 43,15 \\
\hline \multirow{8}{*}{ 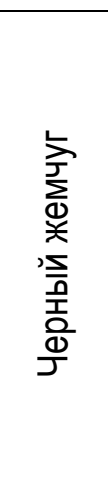 } & Высота ветви, см & 123,93 & 12,30 & 1,74 & 1,40 & 71,23 & 9,93 \\
\hline & Длина плод. зоны ветви, см & 62,87 & 14,71 & 2,08 & 3,31 & 30,22 & 23,40 \\
\hline & Кол-во листьев на 1 ветви, шт. & 90,73 & 36,66 & 5,18 & 5,71 & 17,50 & 40,41 \\
\hline & Кол-во ягод на 1 ветви, шт. & 346,13 & 149,94 & 21,20 & 6,13 & 16,32 & 43,32 \\
\hline & Урожай с куста, г & 5787,51 & 2690,93 & 380,55 & 6,58 & 15,21 & 46,50 \\
\hline & Кол-во плод. ветвей, шт. & 12,80 & 1,30 & 0,18 & 1,44 & 69,42 & 10,19 \\
\hline & Периметр листа, см & 23,91 & 5,57 & 0,56 & 2,33 & 42,92 & 23,30 \\
\hline & Площадь листа, кв. см & 19,66 & 7,28 & 0,73 & 3,71 & 26,99 & 37,06 \\
\hline
\end{tabular}




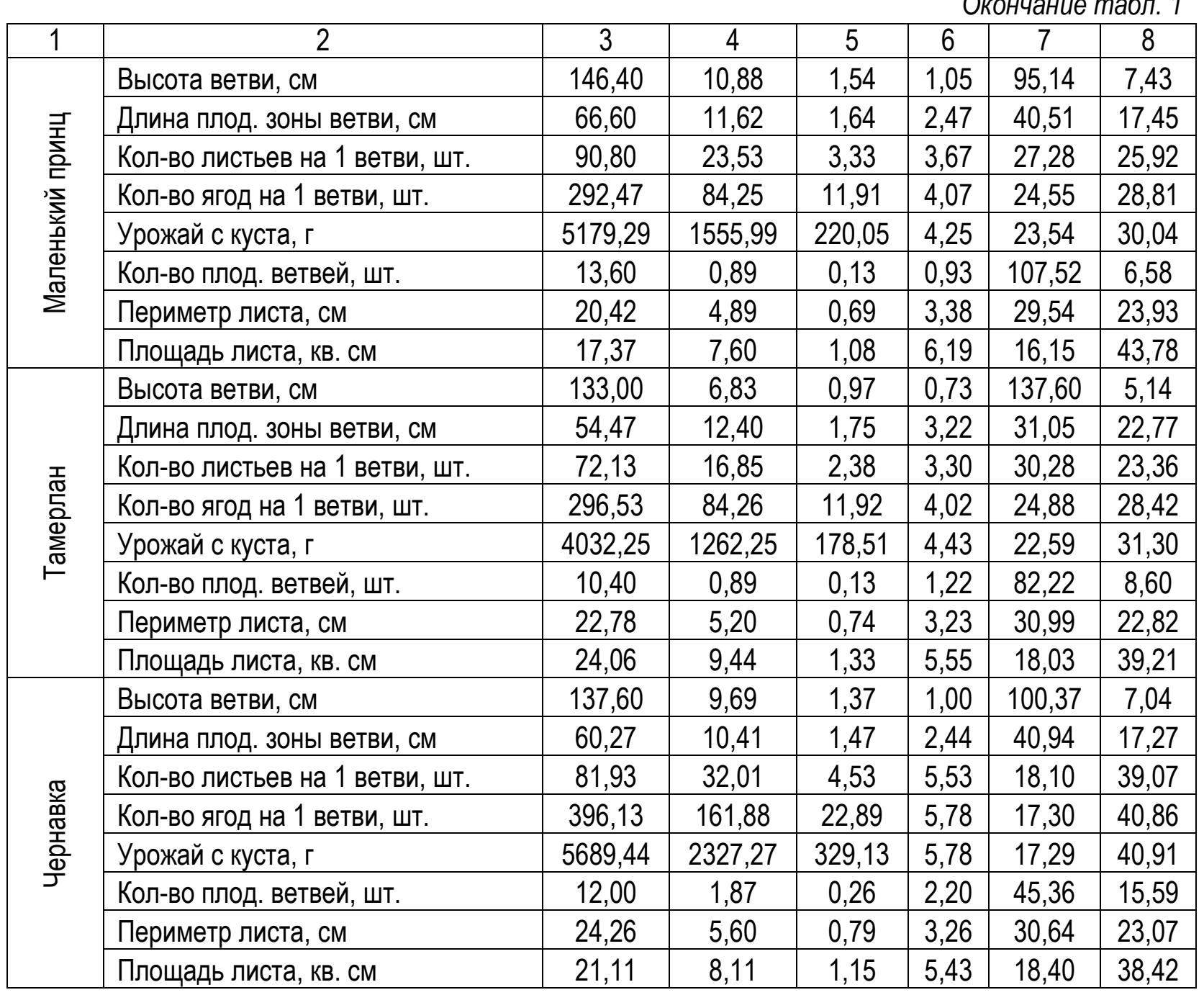

Анализ данных, приведенных в таблице 1, показывает, что у смородины большинство количественных признаков характеризуется средним и высоким варьированием, и это создает трудности при проведении отбора по ним.

Высота побегов колебалась по сортам в среднем от 115,1 $\pm 1,6$ (Зеленая дымка) до $146,4 \pm 1,5$ см (Маленький принц), изменчивость показателя не превышала 10 \%. При этом длина плодоносящей зоны ветви изменялась от 53,5 $\pm 1,2$ (Багира) до 66,6 $\pm 1,6$ см (Маленький принц).

Все функцци живого организма, требующие энергетических затрат, осуществляются за счет внешних источников энергии. Поэтому в основе биологической продуктивности сорта находится фотосинтез. Первичные продукты фотосинтеза под общим направляющим контролем генетического аппарата трансформируются в процессе роста и развития растений в компоненты живой биомассы [5].

К основным показателям фотосинтетической деятельности растений относятся величина площади листьев и динамика ее формирования.

По количеству листьев на 1 плодоносящей ветви сорта различались от 72,1 $\pm 2,4$ (Тамер-

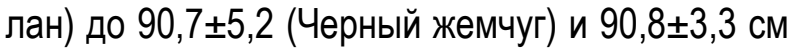
(Маленький принц).

Наиболее крупными листьями характеризует-

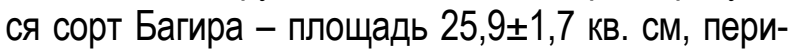

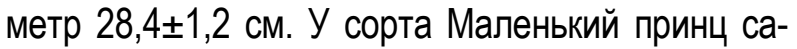

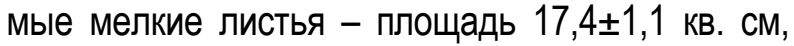
периметр 20,4 $\pm 0,7$ см.

Площадь листьев, приходящаяся на одну ягоду плодоносящей ветви, в среднем колебалась от 4,4 (Чернавка) и 4,6 (Зеленая дымка) до 5,9 кв. см (Багира, Тамерлан). С учетом урожайности наиболее оптимальной площадью листьев, приходящейся на одну ягоду, характеризу- 
ются сорта Черный жемчуг (5,2 кв. см) и Маленький принц (5,4 кв. см). Можно предположить, что большая площадь листьев у сорта Тамерлан позволяет вырабатывать больше ассимилятов, чем это необходимо акцепторам, и излишки продуктов фотосинтеза, накапливаясь в листьях, приводят к депрессии фотосинтеза. В результате продуктивность данного сорта наименьшая среди изучаемых сортов.

Производилась оценка генотипов по слагаемым урожая, так как при отборе ценных форм в селекции основное внимание уделяется сортам с оптимальными хозяйственными параметрами и высоким потенциалом продуктивности. Хозяйственная ценность сорта определяется урожайностью, которая зависит от его биологических особенностей и погодных условий. Анализ экспериментального материала показал, что исследуемые сорта смородины черной характеризуются высокой продуктивностью в Центральном Черноземье.
По количеству ягод на 1 ветви сорта различались от 292,5 (Маленький принц) до 396,1 шт. (Чернавка). При этом варьирование признака составляло 28,4-44,7 \%.

Наибольшая продуктивность характерна для сортов Черный жемчуг, Чернавка и Маленький принц - 5,8 $\pm 0,4 ; 5,7 \pm 0,3$ и 5,2 $\pm 0,2$ кг/куст соответственно. Наименьшая урожайность наблю-

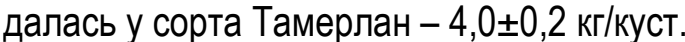

Все компоненты продуктивности вариабельны, так как хотя и обусловлены генотипом сорта, но зависят от агротехнических фракторов, метеорологических условий, устойчивости к болезням и вредителям и т. д.

Одним из показателей продуктивности является коэфффициент продуктивности плодоносящих ветвей, который показывает урожай ягод с одного погонного метра плодоносящей древесины (табл. 2). У изученных сортов коэфффициент продуктивности плодоносящих ветвей был достаточно высоким и изменялся от 570,9 (Maленький принц) до 788,8 (Чернавка).

Таблица 2

\section{Коэффициент продуктивности плодоносящих ветвей}

\begin{tabular}{|l|c|}
\hline \multicolumn{1}{|c|}{ Сорт черной смородины } & Коэфрфициент продуктивности плодоносящих ветвей, г/пог. м \\
\hline Багира & 768,5 \\
\hline Зеленая дымка & 706,7 \\
\hline Черный жемчуг & 715,8 \\
\hline Маленький принц & 570,9 \\
\hline Тамерлан & 707,8 \\
\hline Чернавка & 788,8 \\
\hline
\end{tabular}

Коэфффициент корреляции используется для определения наличия взаимосвязи между свойствами. Поэтому, кроме указанных выше параметров, нами была проведена оценка степени корреляции между показателями роста и плодоношения смородины для каждого сорта.

В результате статистического анализа экспериментальных данных выявлена корреляционная зависимость между количеством ягод и количеством листьев на 1 побеге $(r=0,79)$. По сортам коэфффициент корреляция изменялся от $r=0,67$ (Маленький принц) до $r=0,90$ (Чернавка).

Традиционно наблюдается положительная связь $(r=0,91)$ между периметром и площадью листовой пластинки: от $r=0,85$ (Маленький принц) до $r=0,98$ (Багира).

Зависимость между высотой побега и длиной плодоносящей зоны ветви явно прослеживается для сортов Зеленая дымка, Тамерлан, Маленький принц, Черный жемчуг ( $r=0,55, \ldots, 0,73)$; зависимость между количеством листьев на 1 побеге и длиной плодоносящей зоны ветви наблюдается у сортов Черный жемчуг, Маленький принц, Зеленая дымка $(r=0,56, \ldots, 0,81)$.

В результате проведенного исследования установлено наличие положительной зависимости величины урожая ягод с куста от количества ягод на 1 ветви $(r=0,96)$ и количества листьев $(r=0,75)$. 
Выводы. В результате исследования проведена статистическая оценка вариабельности показателей роста и плодоношения смородины черной шести сортов. Установлена оптимальная площадь листьев, приходящаяся на одну ягоду (5,2-5,4 кв. см). Установлены корреляционные связи между количеством ягод и количеством листьев на одном побеге $(r=0,79)$, величиной урожая ягод с куста и количества листьев $(r=0,75)$. Выделены сорта с высокими уровнями компонентов продуктивности (Черный жемчуг, Чернавка и Маленький принц).

\section{Литература}

1. Бабушкин В.А., Родионов Ю.В., Никитин Д.В., Николашин В.П. и др. Проект наземного роботизируемого комплекса для нужд садоводства и растениеводства // Вестник Мичуринского гос. аграр. ун-та. - 2018. № 4. - C. 6-13.

2. Макова H.E. Статистическая интерпретация показателей роста и плодоношения малины: дис. ... канд. с.-х. наук. - Мичуринск, 2006. - 164 c.

3. Макова Н.Е., Аникьева Э.Н., Аникьев А.А. Статистические свойства биометрических показателей // Плодоводство и ягодоводство России. - 2012. - Т. 34, № 2. - С. 20-29.

4. Аникьев А.А., Макова Н.Е., Аникьева Э.Н., Макова А.А. Автоматизированная система оценки урожайности сортов плодовых и ягодных культур по их морфоометрическим индексам // Робототехника в сельскохозяйственных технологиях: сб. тр. междунар. науч.-практ. конфр. - Мичуринск: БИС, 2014. C. 52-57.
5. Жидехина Т.В. Фотосинтетическая деятельность сортов смородины черной в изменяющихся условиях внешней среды // Плодоводство и ягодоводство России. 2011. - T. 28, № 1.- С. 208-215.

\section{Literatura}

1. Babushkin V.A., Rodionov YU.V., Nikitin D.V., Nikolashin V.P. i dr. Proekt nazemnogo robotiziruemogo kompleksa dlya nuzhd sadovodstva i rastenievodstva // Vestnik Michurinskogo gos. agrar. un-ta. - 2018. № 4. - S. 6-13.

2. Makova N.E. Statisticheskaya interpretaciya pokazatelej rosta i plodonosheniya maliny: dis. ... kand. S.-h. nauk. - Michurinsk, 2006. $164 \mathrm{~s}$.

3. Makova N.E., Anik'eva E.N., Anik'ev A.A. Statisticheskie svojstva biometricheskih pokazatelej // Plodovodstvo i yagodovodstvo Rossii. - 2012. - T. 34, № 2. - S. 20-29.

4. Anik'ev A.A., Makova N.E., Anik'eva E.N., Makova A.A. Avtomatizirovannaya sistema ocenki urozhajnosti sortov plodovyh i yagodnyh kul'tur po in morfometricheskim indeksam // Robototekhnika v sel'skohozyajstvennyh tekhnologiyah: sb. tr. mezhdunar. nauch.-prakt. konf.. - Michurinsk: BIS, 2014. C. 52-57.

5. Zhidekhina T.V. Fotosinteticheskaya deyatel'nost' sortov smorodiny chernoj $v$ izmenyayushchihsya usloviyah vneshnej sredy // Plodovodstvo i yagodovodstvo Rossii. 2011. - T. 28, № 1. - S. 208-215. 